\title{
ABORDAGEM DE GÊNERO NO AMBIENTE ESCOLAR
}

Thamires Maia Paula Oliveira ${ }^{1}$

Karollainy Gonçalves Coelho Carvalho

RESUMO: A presente reflexão tem a intenção de despertar aos leitores um novo olhar sobre a importância da abordagem de gênero e diversidades no ambiente escolar. Sob a crítica reflexiva de hooks e seus estudos de Freire, partimos de que essa abordagem faça parte de uma educação libertadora e transgressora para todos os envolvidos, professores, alunos e comunidade escolar em geral. Em seus trabalhos, a autora demonstrou toda sua paixão por Paulo Freire e a educação libertadora, e reproduziu tanto em sala quanto em seus trabalhos publicados o quanto a pedagogia engajada transformaria as diversidades. A necessidade de termos uma sociedade mais aberta e empática deve partir dos centros educacionais, que são os primeiros transmissores de conhecimentos, para isso, currículos devem ser transformados e adaptados para que essa educação seja realmente efetiva e respeitadora dos direitos dos indivíduos que por sua vez são naturalmente diversos e subjetivos. O contexto histórico sobre gênero precisa ser desmistificado e mais desbravado para que os conceitos impregnados comecem a se dissolver e assim abrir as mentes para um novo olhar e novas concepções.

Palavras-chave: Libertadora. Transformar. Transgredir.

\section{INTRODUÇÃO}

Os séculos se passaram e os estudos relacionados à gênero e diversidade não progrediram o quanto necessita, precisa-se aprender a aprender, para que só após isto, a abordagem desses assuntos seja efetiva na transmissão. Vários estudiosos deixaram suas contribuições para que nos aprofundemos e criemos nossa própria compreensão desses assuntos, bell hooks, entre suas ocupações como professora universitária, filósofa e

' Graduada em Pedagogia pela UNICESUMAR-PR. Pós-graduada em Gestão de pessoas e RH, Mestranda em Educação PPGE - UFT Palmas. E-mail: thamiresmaia@hotmail.com.

2 Graduada em Psicologia pela Faculdade católica Dom Orione (FACDO-TO). E-mail: karollainy84@gmail.com 
escritora, foi uma visionária, ativista antirracista, considerada como um dos intelectuais mais importantes da atualidade, feminista e mulher negra que bradou seus conhecimentos e pesquisas em questões como gênero, feminismo e capitalismo e através destes alcançou local de fala nessa jornada que tanto ainda precisa ser desbravada. Tratar do assunto diversidade no âmbito educacional é algo urgente, já que a escola é um ambiente sistematizado e que tem como dever informar, oferecer fonte de pesquisa, viabilizar meios de discussões coletivas e atingir todos os tipos de diversidade de forma democrática e responsável.

No entanto, as primeiras transformações devem partir primeiramente pelos professores que é quem no primeiro momento transmite o conhecimento ao estudante, que em sua maioria já vem com uma bagagem intelectual e cultural familiar, logo precisa-se inovar, auto atualizar-se e saber moldar de forma individual cada aluno aos novos pensamentos sendo preciso se entregar de forma genuína, ponderada e sensata aos conceitos que serão discutidos. Assim como bell hooks fez como estudante, professora e escritora, por toda sua vida que infelizmente se findou recentemente em 2021, mas através de seus estudos e livros, podemos ter um caminho realmente transgressor para a educação brasileira, local de onde originou seu maior ídolo, Paulo Freire.

O tema gênero ainda em pleno século XXI é tabu em muitas esferas, não sendo diferente na educacional. Infelizmente, a ignorância e a disseminação de ideias corrompidas do assunto, proposita a falta de discussão e transitação do tema no local em que mais deveria ser debatido, a escola.

Ignorar, ou pior, fechar um conceito sobre um assunto que não se tem entendimento, que não foi aprofundado é irresponsável e negacionista, o que causa um verdadeiro atraso na educação transgressor e reflete sucessivamente na sociedade e seu comportamento. 
bell hooks escreveu o livro Ensinando a transgredir (2013), que é um emocionante convite à reflexão de que educação é compromisso e a práxis da liberdade é sempre emancipatória; portanto coletiva e comprometida com a mudança.

Queria que tivessem esta simples definição para ler repetidas vezes e saber que: Feminismo é um movimento para acabar com o sexismo, exploração sexista e opressão. (hooks, bell. 2013 p.ro)

\section{DISCUSSÃO}

Nada foi tão motivador às transformações que a pandemia de 2020, no entanto, se não utilizarmos os tempos atípicos para transformar também nosso interior, pouco valerá todo sofrimento em cada um de formas diferentes atravessaram essa crise social.

"Entender que é necessário transformar o inimigo interno antes que possamos confrontar o inimigo externo" (hooks, bell. 2013, p. 21).

As transgressões devem originar a partir de nós, sem que esperemos do outro para poder agir, para poder comunicar, ensinar e trocar ensinamentos sobre novos assuntos.

De forma muito corajosa e arrojada, bell hooks conta sua história e suas dificuldades em ter lugar de fala nos espaços em que passou tanto como estudante quanto professora. Acrescenta ainda, que apesar das experiências intensamente negativas, se formou acreditando que a educação é ferramenta capacitante à libertação. Com sua perseverança conseguiu inserir-se nos Estudos da Mulher, que até então era lugar somente de mulheres brancas, precisou se blindar do preconceito e da descrença dos que estavam ao seu redor.

Fã e estudiosa dos trabalhos de Paulo Freire, iniciou sua jornada como docente de graduação levando os pensamentos dele para sua sala de aula. Peculiar como culturas tão diferentes, países diferentes, podem culminar pensamentos em comum, nesse caso, o feminismo sob esse novo olhar, ganha leveza e grandeza, afinal, ser feminista para hooks 
sempre foi muito além do que lutar pelos direitos da mulher. Ser feminista é ser democrático, é lutar pela igualdade de raça, sexo, diversidade.

A pedagogia engajada, é uma pedagogia "problematizadora", que propõe não apenas uma visão crítica da realidade, mas um engajamento que se articule para a transformação dela e para que possamos refletir e alcançar, de nada adianta teorias, conceitos e novas diretrizes se delas não se dá a prática, a efetivação, o direito consumado.

"A educação libertadora é a que liga a vontade de saber à vontade de vir a ser" (hooks,bell. 2013, p. 32).

Para que haja mudanças, precisamos inicialmente nos modificar internamente, a autoatualização dos professores é algo de suma importância para que novas práticas pedagógicas comecem a surgir e realmente conquistar o espaço merecido. Nada que é raso é bebido como fonte inesgotável, precisamos cavar poços fundos e cheios, de maneira que mate muitas sedes e que os saciados recomendem aos sedentos. bell hooks nos provoca sobre a urgência de olhar criticamente para as estruturas e refletir sobre quebra de paradigmas com o exemplo do papel da universidade.

Se examinarmos criticamente o papel tradicional da universidade na busca da verdade e na partilha de conhecimento e informação, ficará claro, infelizmente, que as parcialidades que sustentam e mantêm a supremacia branca, o imperialismo, o sexismo e o racismo distorceram a educação a tal ponto que ela deixou de ser uma prática de liberdade. O clamor pelo reconhecimento da diversidade cultural, por repensar os modos de conhecimento e pela desconstrução das antigas epistemologias, bem como a exigência concomitante de uma transformação das salas de aula, de como ensinamos e do que ensinamos, foram revoluções necessárias - que buscam desenvolver a vida a uma academia moribunda e corrupta (hooks, bell. 2013, p. 45).

Ter como objetivo central a pedagogia transformadora é algo mínimo para as discussões das diversidades. Não tem a ver com tirar uma caixa e colocar outra no lugar, como se fosse um bloco de ditatura trocado por um bloco de liberdade, trata-se de 
modificar ideias que congelaram, trata-se de discutir o que realmente é respeitoso para com todos.

Uma concepção histórica e tão enraizada, pode se dissolver trazendo de forma abrangedora e sistêmica na formação inicial e continuada de professores e nos currículos escolares. Trabalhar os conceitos, as questões educacionais que implicam o gênero, ampliar a cultura geral enfatizando a capacidade de aprender a aprender, desenvolver habilidades comunicativas, ter a linguagem informacional dominada, entender e manusear os meios de comunicação e articular aulas com mídias e multimídias explicativas e embasadas em conceitos científicos é um caminho?

A educação é uma escala plural, numerosa e contagiante, então o ponto inicial deve ser de onde não se consiga burlar, de onde seja necessário se cumprir, de onde se tenha subsídios suficientes para a transformação não somente dos papéis, mas da prática deles. O currículo é o norte das escolas, nele se tem a base das práticas educacionais, portanto é ele que deve ser transformado para que com ele, professores, educadores, educandos e a comunidade em geral se transformem.

Através da inserção de novas diretrizes e linhas de conteúdos incluídas nos currículos, teremos uma sociedade mais informada, com ideias clarificadas para que cada um desses sujeitos formule suas próprias conclusões, idealizar algo como pronto e acabado é retrógrado demais para o século XXI.

\section{O ESTERIÓTIPO CONSTRUÍDO}

As condições sociais históricas demonstram como a mulher foi definida com seu corpo apto às atividades domésticas e propriedade do estado, proporcionando riqueza e reprodução ao sistema através de seus trabalhos pré-determinados e fundamentais para sustentar o sistema, enquanto os homens funcionavam como produtores e acumuladores do trabalho enriquecendo e fortalecendo os poderosos senhores capitalistas.

[...] isso é também o que ocorre na atualidade, quando uma nova expansão do mercado de trabalho busca colocar-nos em retrocesso no que tange à 
luta anticolonial e às lutas de outros sujeitos rebeldes - estudantes, feministas, trabalhadores industriais - que nos anos 1960 e 1970 debilitaram a divisão sexual e internacional do trabalho (FEDERICI, 20I7, p.36).

A caça às bruxas foi dissipada no século XVII, no entanto perpetuou-se o mesmo tipo de perseguição às minorias, o capitalismo não acumula somente capital, acumula também as desigualdades. Mulheres, camponeses, comunidades negras, indígenas, e tantas outras minorias, tornaram-se reféns do patriarcalismo mesmo com a evolução e a globalização.

“O feminismo não é somente melhorar a situação das mulheres, é criar um mundo sem desigualdades, sem a exploração do trabalho humano que, no caso das mulheres, se transforma numa dupla exploração" (FEDERICI, 2019).

Tal pensamento abre portas para o debate e argumentação na definição do "lugar de fala" e quem poderia discursar com maior destreza e responsabilidade ao ensinar sobre gênero no âmbito educacional. O termo consiste em dar voz aos que foram historicamente apagados e socialmente excluídos, assim como as máscaras de flandres utilizadas pelos escravos como punição e os calando.

Ao analisar obras como o livro Lugar de Fala, de Djamila Ribeiro e o retrato de Anastásia, escrava castigada com a máscara de flandres, entendemos que as classes silenciadas necessitam de recuperar sua visibilidade e o termo local de fala não consiste em excluir pensamentos, assim como boa parte da população entende, e sim em trazer à discussão pessoas com vivencias pessoais relacionadas ao tema.

Pensando no fato de que as minorias sempre foram discriminadas, associamos as professoras com o gênero feminino, por ser uma profissão majoritária de mulheres, uma das questões a serem tratadas como ponto de partida de novas reflexões e formações. Pois, se elas são maioria no processo da aprendizagem, delas pode-se partir uma nova perspectiva de saberes às crianças que passarem por essa trajetória de saberes.

Para alcançarmos a emancipação que a atualidade exige, carece-se de profissionais que tenham novos olhares, autores de uma nova era onde essas professoras precisam estar em conexão com a realidade, aprimorar e buscar novos tipos de investigação, interação e 
ministração dos saberes, fará parte de um novo capítulo que a educação está escrevendo a favor da pluralidade de ideias. A escola é o lugar onde se aprende não somente conteúdos científicos, mas também vivências, valores e reprodução de um ser totalizado.

Faz-se necessário, também, o intercâmbio entre formação inicial $e$ formação continuada de maneira que a formação dos futuros professores se nutra das demandas da prática e que os professores em exercício frequentem a universidade para discussão e análise de problemas concretos da prática (LIBÂNEO, 20I2, p.4).

O magistério não pode estar desassociado da realidade, a formação dos estudantes deve ser pautada na relação da atuação social, cidadã e em toda a amplitude do contexto vivenciado por eles. Agindo como mediadora e facilitadora do conhecimento, as docentes devem permitir que o estudante construa sua própria opinião e tenha a própria percepção dos conceitos apresentados, a mediação sempre será fundamental, pois ela fará toda a diferença nas hipóteses que poderão ser pensadas.

Por isso, a pedagogia engajada a que hooks nos convida em seu livro é em si a pedagogia da práxis, que por sua vez é libertadora, nasce do concreto, da realidade objetiva das pessoas, de suas dificuldades cotidianas. Ela é importante, pois é em todo tempo um convite à transformação, um convite à cura, um convite à reinvenção da realidade e do olhar.

A própria autora revela que encontrou no conhecimento crítico um lugar de cura para suas questões individuais.

Essa experiência "vivida" de pensamento crítico, de reflexão e análise se tornou um lugar onde eu trabalhava para explicar a mágoa e fazê-la ir embora. Fundamentalmente essa experiência me ensinou que a teoria pode ser um lugar de cura (hooks, 2013, p. 85).

Em outro momento, ela chega a afirmar que esse pensamento arrebatador e engajado que ela propaga vem sendo capaz de tirar as pessoas de um lugar adoecedor e de conformismo e de lhes oferecer uma nova perspectiva de pensamento, de cura, de liberdade:

Segurava as minhas mãos e repetia: "Tinha uma dor tão grande dentro de mim”. Agradeceu porque nosso encontro, nossa teorização (...) havia 
aliviado a sua dor. Testemunhou que sentiu a dor ir embora. Sentiu uma cura acontecendo dentro dela (hooks, 2013, p. 102).

Acreditamos, então, que a educação, para ser engajada e emancipadora, deve caminhar na perspectiva de fazer sentido para as pessoas, de dialogar com o cotidiano delas, de expor as suas feridas e de curá-las, de desnudar seus sensos comuns, de atravessálas e potencializá-las para a vida, para a luta.

No entanto, para isso, é necessário romper com velhas concepções de educação que ainda estão tão presentes nas escolas. É necessário nos posicionar frontalmente contra um modelo de educação que limita a visão de mundo, as possibilidades de vir a ser e de existir, que diminui a consciência crítica, que naturaliza os fenômenos sociais, que torna reduzidas as formas de aprender.

Não obstante, é fundamental confrontar, em nossas práticas como educadores, qualquer forma de cerceamento do corpo e da mente do outro, pois consideramos que o conhecimento é liberdade e não prisão. É ponte e não muro. Nesse sentido, Foucault (1987) é muito oportuno ao apontar em seu livro Vigiar e Punir as formas de controle que se dão nos espaços escolares sobre os indivíduos ali envolvidos.

\section{CONSIDERAÇÕES FINAIS}

Diante as exposições, é certo afirmar que quanto mais discussões fizermos, mais próximos estaremos de transformações efetivas. Tratar de novas causas sempre será desafiador e é exatamente por isso a necessidade da união das forças de todos que já conseguem visualizar a urgência dessa progressão dentro da educação.

Vivemos em um país onde a diversidade é um dos seus patrimônios naturais, povos culturalmente subjetivos e riquezas tão particulares que infelizmente não são enaltecidas como mereciam, portanto, cabe a nós iniciarmos a transformação, cabe a nós, chamarmos a todos para essa discussão.

Oportunizar o lugar de fala para pessoas que com propriedade façam apresentações de possibilidades curriculares que abordem o tema gênero como conteúdo obrigatório 
desde as séries iniciais, desbravar o contexto histórico desmistificando os estereótipos criados por poderes capitalistas, ofertar formação continuada aos professores para que como hooks e Freire, aprendam a aprender novamente, são pontos iniciais para uma jornada que muito ainda precisamos desbravar.

\section{REFERÊNCIAS}

ECA - Estatuto da criança e do adolescente, promulgada em 13/07/1990, publicada no DOU de 16/o7/1990 e retificada no DOU de 27/09/1990.

FEDERICI, Silvia. Calibã e a bruxa: mulheres, corpo e acumulação primitiva. São Paulo: Editora Elefante, 2017.

hooks, bell. Ensinando a transgredir: a educação como prática da liberdade. São Paulo Martins Fontes, 2013.

LIBÂNEO, J.C. Adeus professor, adeus professora? Novas exigências educacionais e profissão docente. 13. Editora São Paulo: Cortez, 2012. 